\title{
Interaction between the DNAH9 gene and early smoke exposure in bronchial hyperresponsiveness
}

\author{
Marie-Hélène Dizier ${ }^{1,2}$, Rachel Nadif $3,4,11$, Patricia Margaritte-Jeannin ${ }^{1,2,11}$, \\ Sheila J. Barton ${ }^{5}$, Chloé Sarnowski ${ }^{1,2,6}$, Valérie Gagné-Ouellet ${ }^{7}$, \\ Myriam Brossard ${ }^{1,2,6}$, Nolwenn Lavielle ${ }^{1,2,6}$, Jocelyne Just ${ }^{8}$, Mark Lathrop ${ }^{9}$, \\ John W. Holloway ${ }^{10}$, Catherine Laprise ${ }^{7,11}$, Emmanuelle Bouzigon ${ }^{1,2,11}$ and \\ Florence Demenais ${ }^{1,2}$
}

\begin{abstract}
Affiliations: ${ }^{1}$ INSERM, UMR 946, Genetic Variation and Human Diseases Unit, Paris, France. ${ }^{2}$ Université Paris Diderot, Sorbonne Paris Cité, Institut Universitaire d'Hématologie, Paris, France. ${ }^{3}$ INSERM, U1168, Aging and Chronic Diseases, Epidemiological and Public Health Approaches (VIMA), Villejuif, France. ${ }^{4}$ Université Versailles Saint-Quentin-en-Yvelines, UMR_S 1168, Paris, France. ${ }^{5}$ MRC Lifecourse Epidemiology Unit, Faculty of Medicine, University of Southampton, Southampton, UK. 'Université Paris-Sud, UMR_S 1018, Villejuif, France. "Université du Québec, Chicoutimi, Canada. ${ }^{8}$ Service d'Allergologie Pédiatrique, Centre de l'Asthme et des Allergies, Hôpital d'Enfants Armand-Trousseau (APHP) - Sorbonne Universités, UPMC Université Paris 06, UMR S 1136, Institut Pierre Louis d'Epidémiologie et de Santé Publique, Equipe EPAR, Paris, France. ${ }^{9}$ McGill University and Genome Quebec's Innovation Centre, Montréal, Canada. ${ }^{10}$ Human Development and Health, Faculty of Medicine, University of Southampton, Southampton, UK. ${ }^{11}$ These authors contributed equally to this work.
\end{abstract}

Correspondence: Marie-Hélène Dizier, UMR 946, INSERM/Université Paris-Diderot, 27 rue Juliette Dodu, 75010 Paris, France. E-mail: Marie-Helene.Dizierdinserm.fr

ABSTRACT A previous genome-wide linkage scan of bronchial hyperresponsiveness (BHR) in the French Epidemiological study on the Genetics and Environment of Asthma (EGEA) families, performed in the presence of a genexearly-life environmental tobacco smoke (ETS) exposure interaction, showed the strongest interaction in the $17 \mathrm{p} 11$ region where linkage was detected only among unexposed siblings. Our goal was to conduct fine-scale mapping of $17 \mathrm{p} 11$ to identify single nucleotide polymorphisms (SNPs) interacting with ETS that influence BHR.

Analyses were performed in 388 French EGEA asthmatic families, using a two-step strategy: 1) selection of SNPs displaying family-based association test (FBAT) association signals $(\mathrm{p} \leqslant 0.01)$ with BHR in unexposed siblings, and 2) a FBAT homogeneity test between exposed and unexposed siblings plus a robust log-linear interaction test.

A single SNP reached the threshold $\left(\mathrm{p} \leqslant 3 \times 10^{-3}\right)$ for significant interaction with ETS using both interaction tests, after accounting for multiple testing. Results were replicated in 253 French-Canadian families, but not in 341 UK families, probably due in part to differences in phenotypic features between datasets.

The SNP showing significant interaction with ETS belongs to DNAH9 (dynein, axonemal, heavy chain 9), a promising candidate gene involved in respiratory cilia mobility and associated with primary ciliary dyskinesia, a disease associated with abnormalities of pulmonary function.

@ERSpublications

An interaction between the DNAH9 gene and early smoke exposure in bronchial hyperresponsiveness was found http://ow.ly/V9qft 


\section{Introduction}

Asthma is a common respiratory disease characterised by airway inflammation, reversible airflow obstruction and bronchial hyperresponsiveness (BHR). BHR is a feature of asthma and it also constitutes an important risk factor for asthma [1]. BHR is due to increased sensitivity of the airways to physical and chemical stimulants, such as cold air and cigarette smoke, and to pharmacological agents, such as methacholine and histamine. Both asthma and BHR result from multiple genetic and environmental factors that may interact. Many genetic studies based on positional cloning approaches and genome-wide association studies (GWAS) have been conducted for asthma and BHR [2]. These studies, which have largely focused on association between disease and individual genetic polymorphisms, have been successful in identifying susceptibility genes [2]. However, all these genes account for only a small proportion of heritability [3]. To further our understanding of the genetic basis of complex diseases, current studies are now extending to more complex analyses, taking into account phenotypic heterogeneity and genexgene or genexenvironment interactions. For asthma and BHR, for which the involvement of environment factors has been shown to be substantial, it appears of major interest to include genexenvironment interactions in genetic studies. Among the environmental factors associated with asthma and BHR, maternal smoking during pregnancy and early-life environmental tobacco smoke (ETS) exposure are important risk factors [4]. GenexETS interactions underlying susceptibility to asthma and asthma-related phenotypes were first evidenced in the context of genome-wide linkage scans [5-7] and by association studies with candidate genes, including $A D R B 2$ ( $\beta_{2}$-adrenergic receptor) [8], GSTM1 (glutathione $S$-transferase M1) [9], GSTT1 (glutathione S-transferase T1) [9] and GSTP1 (glutathione $S$-transferase P1) [10]. Genetic variants at the $17 \mathrm{q} 21$ locus that were detected by a GWAS of childhood asthma [11] were shown to confer an increased risk of early-onset asthma in subjects exposed to early-life ETS first in the French Epidemiological study on the Genetics and Environment of Asthma (EGEA) study [12] and, subsequently, in other studies [13-15]. PCDH1 (protocadherin 1) and ADAM33 (ADAM metallopeptidase domain 33) genes that were identified as susceptibility genes for BHR through positional cloning $[16,17]$ were also found to interact with ETS exposure in utero and/or in early life $[16,18,19]$. More recently, a meta-analysis of genome-wide interaction studies (GWIS) of childhood asthma suggested the potential interaction of a number of genes with ETS exposure [20].

A previous genome-wide linkage scan of BHR in EGEA families, performed in the presence of genexETS exposure interaction, showed the strongest interaction in the $17 \mathrm{p} 11$ region [7], where linkage was detected only among unexposed siblings. Our goal was to conduct fine-scale mapping of this region to identify genetic variants interacting with ETS exposure in BHR susceptibility. A two-step strategy using the family-based association test (FBAT) [21] was conducted in the discovery sample of 388 French EGEA families ascertained through asthmatic probands. We validated our results by another interaction test based on a log-linear model in case-parent triads [22], and by replication analysis in two other asthma-ascertained family samples that consisted of 253 French-Canadian families and $341 \mathrm{UK}$ families.

\section{Materials and methods \\ Discovery sample}

The EGEA study and the inclusion criteria have been described in detail previously [23]. The EGEA family sample consisted of 388 French nuclear families that included 253 families ascertained through offspring with asthma (one offspring proband in $90 \%$ of families and two offspring probands in the remainder) and 135 families ascertained through one parent with asthma.

As in the previous linkage analysis [7], the BHR phenotype was defined according to the results of the methacholine bronchial challenge test. Participants with a provocative dose of methacholine causing a $\geqslant 20 \%$ fall in their baseline forced expiratory volume in $1 \mathrm{~s}\left(\mathrm{FEV}_{1}\right)(\mathrm{PD} 20)$ of $\leqslant 4 \mathrm{mg} \cdot \mathrm{mL}^{-1}$ had BHR, while participants that did not show a fall in $\mathrm{FEV}_{1}$ did not have BHR. This binary BHR phenotype (yes/no for $\mathrm{BHR}$ ) will be subsequently designated as BHR. The protocol of the methacholine challenge test has been described in detail elsewhere [23].

The definition of ETS exposure in early childhood in the current study was the same as that used for the previous linkage analysis [7], and in the identification of interaction of ETS with 17q21 variants in EGEA

Support statement: The French EGEA study was partly funded by grants from the French National Agency for Research (ANR 05-SEST-020-02/05-9-97, ANR 06-CEBS, ANR-11-BSV1-027-GWIS-AM). Genotyping of the asthma-ascertained samples was supported by grants from the European Commission (018996) and the French Ministry of Higher Education and Research. We also acknowledge Region Ile de France (DIM-SEnT 2011) and Fondation pour la recherche Médicale (FRM 2013) for their support. The Canada Research Chair on Genetic Determinants of Asthma held by C. Laprise since 2005 allows the maintenance of the French-Canadian study. The Southampton asthma family cohort (SOTON) was originally recruited in collaboration with Genome Therapeutics Corp. and Schering-Plough. Genotyping was supported by the Asthma, Allergy and Inflammation Research (AAIR) Charity. Funding information for this article has been deposited with FundRef.

Conflict of interest: None declared. 
families [12] and subsequent replication studies [13-15]. ETS exposure was defined as follows: 1) for an adult, by a positive answer to the question: "Did your mother or your father smoke during your early childhood?"; 2) for a child, by a positive answer to the question asked to the child's mother (or father): "Did you or the father (or the mother) of your child smoke when your child was less than 2 years old?". We did not use information on in utero exposure to tobacco smoke since all mothers who smoked during pregnancy continued to smoke during the early childhood of their offspring.

\section{Replication studies}

The Saguenay-Lac-Saint-Jean (SLSJ) asthma study comprised 253 French-Canadian multigenerational families ascertained through two probands with asthma [24]. Inclusion criteria of probands have been described previously [24].

The UK Southampton asthma family cohort (SOTON) has been described in detail previously [25]. A total of 341 Caucasian families were recruited from the Southampton area with at least two siblings (age 5-21 years) with a current physician diagnosis of asthma and taking asthma medication on a regular basis [25]. The BHR (PD20) phenotype and ETS exposure were defined in the SLSJ and SOTON studies in an identical manner as in the EGEA study.

\section{Genotyping}

The EGEA subjects were genotyped using an Illumina 610 Quad array (Illumina, San Diego, CA, USA) at the Centre National de Génotypage (CNG, Evry, France), as part of the European GABRIEL asthma consortium [26]. Stringent quality criteria, as detailed previously [26], were used to select both individuals and SNPs for analysis. For this study, we used 1732 SNPs belonging to the 17 p11 region within an interval of $5 \mathrm{Mb}$ on each side of the linkage peak, located at $16 \mathrm{Mb}$ from pter. The SLSJ sample was also genotyped at CNG using an Illumina 610 Quad array. The same quality control criteria for individuals and markers as used for EGEA applied to this dataset. The SOTON family sample was genotyped using custom (not genome-wide) genotyping which was performed by LGC Genomics (Hoddesdon, Hertfordshire, UK; www.lgcgenomics.com), using a proprietary competitive allele-specific PCR genotyping system (KASPar).

\section{Statistical analysis}

Analysis of the EGEA discovery sample

Two-step analysis using FBAT

As the $17 \mathrm{p} 11$ region was detected through linkage analysis, analyses were conducted using the FBAT approach [21], which tests for association in presence of linkage. We assumed an additive genetic model and used the "-e" option [27] for an empirical estimator of the variance, which makes the association test robust to the dependency between siblings and allows use of all siblings in a family.

To limit the problem of multiple testing, we applied a two-step strategy consisting in a first step of SNP selection followed by a second step of interaction tests. Such a strategy is currently used for interaction studies based on a large panel of markers to reduce the loss of power due to the correction for multiple testing $[28,29]$. As linkage to $17 \mathrm{p} 11$ had been previously detected in unexposed siblings only [7], in the first step we selected SNPs indicating FBAT association signals with BHR in the same group of unexposed siblings using a nonstringent threshold (as usually recommended in two-step strategies) of $1 \%$. In the second step, we searched for SNP $\times$ ETS interactions by testing the homogeneity of the SNP-BHR association between exposed and unexposed siblings using FBAT [30]. This test was applied to SNPs selected at the first step. As presence of association signals in unexposed siblings does not rely on the presence of a SNP $\times$ ETS interaction (i.e. different effect of SNPs between exposed and unexposed siblings), these two steps are independent. Consequently, correction for multiple testing at the second step used the Bonferroni correction for the number of SNPs selected at the first step.

\section{Validation analysis using the Umbach-Weinberg method}

In order to validate significant interactions found with the FBAT homogeneity test, we applied the log-linear modelling approach for testing interaction in triads (case and parents) as proposed by UMBACH and Weinberg [22]. This approach allows adjusting on the genotypic parental mating of each sibling and thus avoids bias due to population stratification. A different distribution of parental genotypic matings between exposed versus unexposed siblings, due to population stratification, may lead to different transmission probabilities in the two groups and consequently to false detection of interaction. FBAT is thus less robust than the Umbach-Weinberg method as FBAT only adjusts for the genotypic parental distribution within the exposed and unexposed groups of siblings. However, the Umbach-Weinberg method is less powerful than FBAT since it can be applied to only one sibling per family. The log-linear analysis was first conducted using the youngest siblings for whom the information on ETS exposure was the closest in time with respect to BHR occurrence and thus the least influenced by potential recall bias. 
The analysis was also performed by considering the oldest siblings, but similar results were obtained and thus are not presented. Note that in EGEA, more than two-thirds of families have only one sibling having BHR, making the choice of siblings irrelevant, and explaining at least in part the similarity of results with the youngest and oldest siblings. Moreover, this indicates that the overall familial dependency was not large.

Finally, to avoid any bias caused by the selection of one sibling per family, we applied a UmbachWeinberg-like method to all siblings while taking into account the dependency between siblings. For that purpose, we used the log-linear (Poisson regression) model with the robust estimator of variance [31], as implemented in Stata version 12 (Stata Corporation, College Station, TX, USA). Note that such analysis was performed in EGEA only because of problems encountered in estimating robust standard errors in the other datasets.

As for FBAT analysis, all these analyses assumed an additive genetic model and the same correction for multiple testing was applied, i.e. Bonferroni correction according to the number of SNPs selected at the first step.

\section{Replication analysis in SLSJ and SOTON families}

SNPs showing significant interaction with ETS from both FBAT homogeneity and Umbach-Weinberg tests in the discovery sample were analysed in the replication samples using the same two interaction tests. To declare an interaction to be validated in replication samples, we again applied a Bonferroni correction to the number of SNPs tested in these samples.

\section{Results}

\section{Data description}

The characteristics of genotyped siblings having BHR in EGEA, SLSJ and SOTON families are shown in table 1.

A total of 304 siblings (from 189 families) had BHR in EGEA, 145 (from 120 families) in SLSJ and 382 (from 258 families) in SOTON. Among these siblings, the proportion of atopic subjects was similar in the three datasets (ranging between $76 \%$ and $86 \%$ ), while the proportion of asthmatics was higher in SLSJ and SOTON (95\%) than in EGEA (60\%). The proportions of females in siblings with BHR were similar in the three datasets, ranging between $43 \%$ and $52 \%$. In contrast, these siblings were younger in SOTON with a mean age of 10.6 years (95\% CI 8.0-13.8) than those in EGEA and SLSJ with respective mean ages of 16.1 years (95\% CI 15.2-17.0) and 20.3 years (95\% CI 18.6-22.0). Similarly, the mean of age at onset of asthma was lower in SOTON (4.4 years, 95\% CI 4.0-4.7) than in EGEA (7.4 years, 95\% CI 6.3-8.6) and SLSJ (9.4 years, 95\% CI 7.7-11.0). Finally, only $29.8 \%$ of siblings with BHR were exposed to ETS in SOTON, while that proportion was $58 \%$ in EGEA and $64 \%$ in SLSJ.

\section{Analysis of genexETS interactions}

The results of the EGEA discovery sample are shown in table 2.

FBAT analysis of the 17 p11 region, conducted in EGEA unexposed siblings, showed association of 16 SNPs (after removing SNPs in complete linkage disequilibrium) with BHR $(\mathrm{p} \leqslant 0.01)$. When using the FBAT homogeneity test between exposed versus unexposed siblings, one of these SNPs showed a significant interaction after accounting for multiple testing $\left(\mathrm{p}=0.05 / 16=3 \times 10^{-3}\right)$, i.e. $\mathrm{p}=8 \times 10^{-4}$ for rs 7225157 , and one

TABLE 1 Phenotypic features of genotyped siblings having bronchial hyperresponsiveness in the Epidemiological study on the Genetics and Environment of Asthma (EGEA), SaguenayLac-Saint-Jean (SLSJ) asthma study and Southampton asthma family cohort (SOTON) asthma-ascertained families

\begin{tabular}{lccc} 
& EGEA & SLS & SOTON \\
\hline Subjects & 304 & 145 & 382 \\
Age years & $16.1(15.2-17.0)$ & $20.3(18.6-22.0)$ & $10.6(8.0-13.8)$ \\
Females & $43.4(132)$ & $52.4(76)$ & $44.5(170)$ \\
Asthma & $59.5(181)$ & $95.2(138)$ & $94.8(362)$ \\
Age at asthma onset years & $7.4(6.3-8.6)$ & $9.4(7.7-11.0)$ & $4.4(4.0-4.7)$ \\
Atopy & $76.0(228)$ & $85.8(121)$ & $77.5(296)$ \\
ETS exposure & $57.9(176)$ & $64.1(93)$ & $29.8(114)$ \\
\hline
\end{tabular}

Data are presented as n, mean $(95 \% \mathrm{CI})$ or \% (n). ETS: environmental tobacco smoke. 
TABLE 2 Results of the two-step strategy investigating genexenvironmental tobacco smoke (ETS) exposure in the 17p11 region in the Epidemiological study on the Genetics and Environment of Asthma (EGEA) discovery sample

\begin{tabular}{|c|c|c|c|c|c|c|c|c|c|c|c|c|c|c|c|}
\hline SNP \# & $\begin{array}{c}\text { Position } \\
\text { bp }\end{array}$ & Gene & Location & MAF & \multicolumn{3}{|c|}{$\begin{array}{c}\text { ETS } \\
\text { unexposed (1) }\end{array}$} & \multicolumn{3}{|c|}{ ETS exposed (2) } & \multicolumn{2}{|c|}{$\begin{array}{c}\text { FBAT } \\
\text { homogeneity } \\
\text { test between } \\
\text { (1) and (2) }\end{array}$} & \multicolumn{3}{|c|}{$\begin{array}{l}\text { Umbach-Weinberg } \\
\text { interaction test }^{f}\end{array}$} \\
\hline rs7225157 & 11680785 & DNAH9 & Intron & 0.17 & 39 & -2.66 & 0.008 & 52 & 2.09 & 0.037 & 11.22 & 0.0008 & 188 & 3.08 & 0.0016 \\
\hline rs1519255 & 12583672 & MYOCD & Intron & 0.13 & 28 & 3.12 & 0.002 & 35 & 0.91 & 0.362 & 8.31 & 0.0040 & 189 & -2.07 & 0.0356 \\
\hline rs2323052 & 13780923 & $\operatorname{cox} 10$ & $\begin{array}{c}\text { Flanking } 5^{\prime} \\
\text { UTR }\end{array}$ & 0.07 & 29 & -2.72 & 0.007 & 23 & 0.25 & 0.803 & 2.79 & 0.0947 & & & \\
\hline rs6502310 & 13784815 & $\operatorname{cox} 10$ & $\begin{array}{l}\text { Flanking } 5^{\prime} \\
\text { UTR }\end{array}$ & 0.09 & 34 & -2.68 & 0.007 & 32 & 0.52 & 0.600 & 4.01 & 0.0452 & & & \\
\hline rs4792411 & 13797101 & $\operatorname{cox} 10$ & $\begin{array}{c}\text { Flanking } 5^{\prime} \\
\text { UTR }\end{array}$ & 0.10 & 28 & -2.89 & 0.004 & 34 & 1.19 & 0.236 & 7.21 & 0.0072 & & & \\
\hline rs11649913 & 14547787 & FLJ45831 & $\begin{array}{c}\text { Flanking } 3^{\prime} \\
\text { UTR }\end{array}$ & 0.26 & 40 & 3.16 & 0.002 & 58 & 1.61 & 0.108 & 1.57 & 0.2102 & & & \\
\hline rs6502405 & 14834158 & FLJ45831 & $\begin{array}{c}\text { Flanking } 5^{\prime} \\
\text { UTR }\end{array}$ & 0.39 & 44 & 2.57 & 0.010 & 66 & -0.33 & 0.742 & 4.50 & 0.0339 & & & \\
\hline rs12942402 & 15371906 & FLJ36674 & $\begin{array}{c}\text { Flanking } 5^{\prime} \\
\text { UTR }\end{array}$ & 0.26 & 48 & 2.69 & 0.007 & 60 & -0.75 & 0.451 & 5.48 & 0.0192 & & & \\
\hline rs1971043 & 20043515 & SPECC1 & $\begin{array}{c}\text { Flanking } 5^{\prime} \\
\text { UTR }\end{array}$ & 0.16 & 33 & -2.97 & 0.003 & 51 & -2.31 & 0.021 & 0.04 & 0.8358 & & & \\
\hline rs7209889 & 20217122 & SPECC1 & $\begin{array}{c}\text { Flanking } 3^{\prime} \\
\text { UTR }\end{array}$ & 0.15 & 32 & -2.75 & 0.006 & 49 & -1.72 & 0.086 & -0.15 & & & & \\
\hline rs4473257 & 20823268 & MGC87631 & $\begin{array}{c}\text { Flanking } 5^{\prime} \\
\text { UTR }\end{array}$ & 0.26 & 44 & 2.60 & 0.009 & 58 & 0.43 & 0.665 & 2.58 & 0.1085 & & & \\
\hline
\end{tabular}

SNP: single nucleotide polymorphism; MAF: minor allele frequency; FBAT: family-based association test; UTR: untranslated region. " : all SNPs showing $p \leqslant 0.01$ with FBAT in unexposed siblings; ${ }^{\text {П: }}$ dbSNP (build 37.1); ${ }^{+}$: number of informative families for FBAT; §: Chi-squared test (1 degree of freedom); $f_{\text {: }}$ applied only to SNPs reaching or being close to the significance level of interaction $\left(p \leqslant 3 \times 10^{-3}\right)$ with the FBAT homogeneity test; ${ }^{\# \#}$ : number of siblings (only one per family using the Umbach-Weinberg method).

approached significance, i.e. $\mathrm{p}=4 \times 10^{-3}$ for $\mathrm{rs} 1519255$ (figure 1). The interaction with rs7225157 was also found significant with the Umbach-Weinberg method $\left(\mathrm{p}=1.6 \times 10^{-3}\right)$ and was thus validated, while this was not the case for $\mathrm{rs} 1519255$ ( $\mathrm{p}=0.04$ ). Note that when using the Umbach-Weinberg-like method applied to all siblings in EGEA, the interaction with rs7225157 reached $\mathrm{p}=10^{-5}$, thus largely exceeding the significance threshold and strengthening our finding.

The minor allele of rs7225157 was negatively associated with BHR in ETS-unexposed siblings and positively in ETS-exposed siblings.

Thus, only rs7225157 was taken forward in the replication samples (table 3).

In SLSJ, interaction with ETS exposure was significantly detected with the same direction effect as in EGEA using both the FBAT homogeneity test $(\mathrm{p}=0.04)$ and Umbach-Weinberg method $(\mathrm{p}=0.03)$.

However, there was no replication of interaction of ETS with rs7225157 in SOTON families, using either the FBAT homogeneity test $(\mathrm{p}=0.2)$ or Umbach-Weinberg method $(\mathrm{p}=0.43)$.

\section{Discussion}

This study identified a genetic variant in the $17 \mathrm{p} 11$ region involved in BHR and interacting with ETS exposure. Significant interaction with ETS was detected in the linkage region previously reported in the French EGEA families [7]. Evidence for this interaction rests on the significant results obtained in the large EGEA discovery family sample using FBAT and validated by the log-linear modelling approach, which is robust to population stratification. Replication of these results was further obtained in 
a)

a)

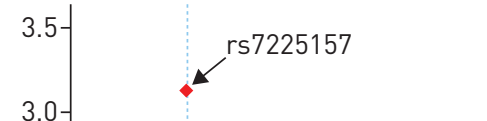

Linkage peak

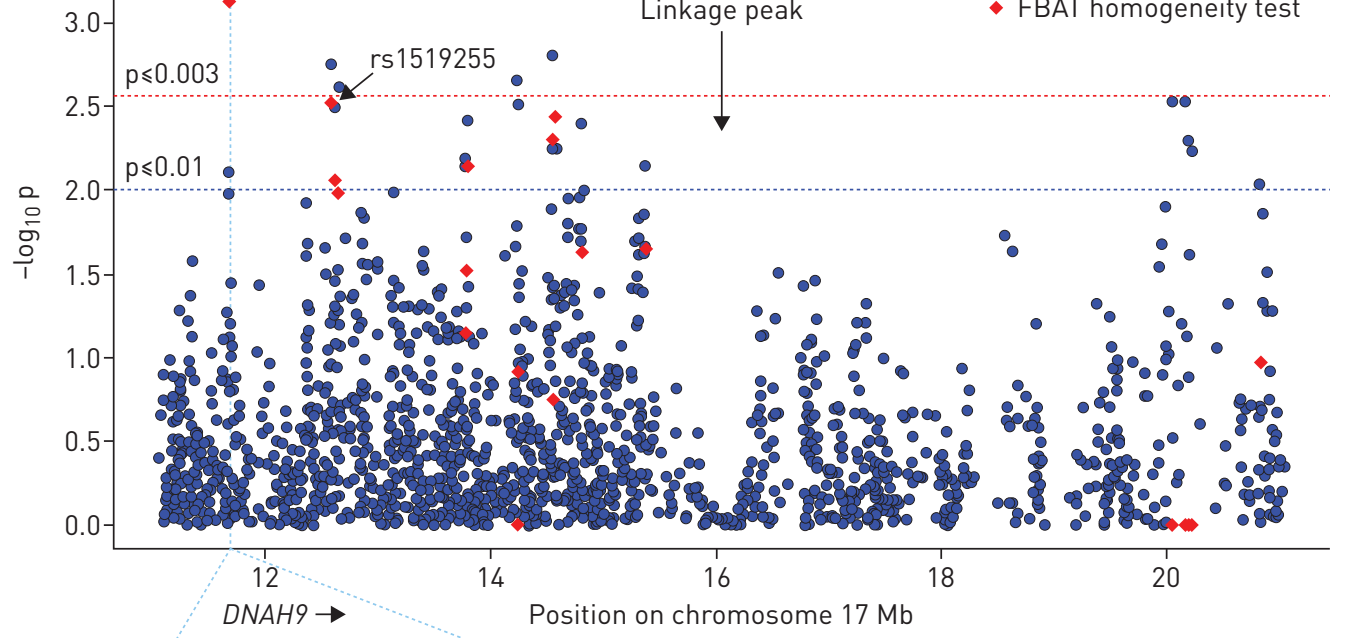

b)

0
$\circ$
$ㅇ$
1

1
0
0
$\frac{0}{1}$

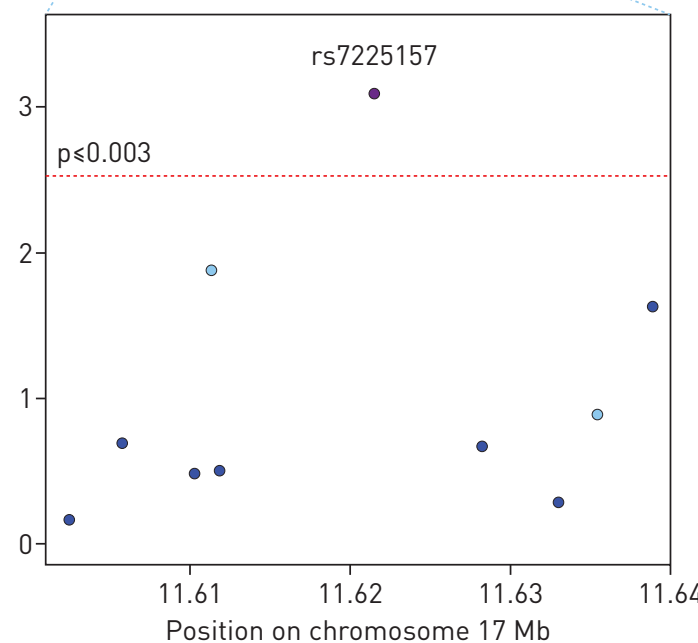

In discovery sample (EGEA)

- FBAT in ETS-unexposed

FBAT homogeneity test

FBAT homogeneity test in discovery sample (EGEA)

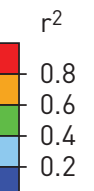

FIGURE 1 a) Plots using the 1732 single nucleotide polymorphisms (SNPs) in the 17p11 linkage region (11-21 Mb from pter) of family-based association test (FBAT) results (expressed as $-\log _{10} p$ ) in French Epidemiological study on the Genetics and Environment of Asthma (EGEA) early-life environmental tobacco smoke (ETS)-unexposed siblings and results of the FBAT homogeneity test (expressed as $-\log _{10} \mathrm{pl}$ applied to EGEA siblings for SNPs having FBAT $-\log _{10} p \geqslant 2$ in unexposed siblings. b) Visualisation of the results in the interval of associated SNPs (spanning $20 \mathrm{~kb}$ on each side of rs7225157) using LocusZoom software (http://locuszoom.sph. umich.edu/locuszoom//. The $y$-axis shows the $-\log _{10} \mathrm{p}$ values of FBAT homogeneity tests in the EGEA discovery sample. The position of the SNPs in megabases (dbSNP, build 37.1) is shown on the x-axis. The SNP rs7225157 is coloured purple and the degree of linkage disequilibrium (from the 1000 Genomes reference panel; www.1000genomes.org) between that SNP and the other SNPs is indicated by colour according to the key (red being the highest degree of linkage disequilibrium).

French-Canadian families using both methods. Our results were thus strengthened both by validation at the statistical methodology level and by replication at the population level.

No replication of 17 p11 SNP $\times$ ETS exposure interaction was observed in the SOTON families. This lack of replication may reflect heterogeneity between datasets in terms of genetic background, ETS exposure, phenotypic characteristics and/or ascertainment mode. Indeed, the SOTON siblings differ from EGEA and SLSJ siblings with respect to both frequency of ETS exposure and phenotypic features. The proportion of ETS-exposed siblings is smaller in SOTON than in EGEA and SLSJ siblings (one-third versus two-thirds). Moreover, the frequency of asthma in SOTON siblings with BHR (95\%) is much larger than in EGEA siblings (60\%). Furthermore, SOTON siblings are younger and have a younger mean age at asthma onset than EGEA and SLSJ siblings, as described in the Results section. Asthma with a younger age at onset may indeed depend on a stronger gene effect and a smaller ETS effect, making genexETS interaction more 
TABLE 3 Analysis of genexenvironmental tobacco smoke (ETS) interaction in the discovery (Epidemiological study on the Genetics and Environment of Asthma (EGEA)) and replication (Saguenay-Lac-Saint-Jean (SLSJ) asthma study and Southampton asthma family cohort (SOTON)] samples for rs7225157

\begin{tabular}{|c|c|c|c|c|c|c|c|c|c|c|c|c|}
\hline \multirow[t]{3}{*}{ SNP } & \multirow{3}{*}{$\begin{array}{l}\text { Position } \\
\text { bp }\end{array}$} & \multirow{3}{*}{$\begin{array}{l}\text { Minor/ } \\
\text { major } \\
\text { allele }\end{array}$} & \multirow[t]{3}{*}{ MAF } & \multicolumn{9}{|c|}{ FBAT homogeneity test } \\
\hline & & & & \multicolumn{3}{|c|}{ EGEA } & \multicolumn{3}{|c|}{ SLSJ } & \multicolumn{3}{|c|}{ SOTON } \\
\hline & & & & $n^{\pi}$ & $\chi^{2 \S}$ & $\mathbf{p}$ & $n^{\text {ๆ }}$ & $\chi^{2}$ & $\mathbf{p}$ & $n$ ๆ & $\chi^{2 \S}$ & $\mathbf{p}$ \\
\hline \multirow[t]{5}{*}{ rs7225157 } & 11680785 & $\mathrm{G} / \mathrm{A}$ & 0.172 & 89 & 11.22 & 0.0008 & 56 & 4.32 & 0.038 & 97 & 1.60 & 0.2 \\
\hline & & & & \multicolumn{9}{|c|}{ Umbach-Weinberg test } \\
\hline & & & & \multicolumn{3}{|c|}{ EGEA } & \multicolumn{3}{|c|}{ SLSJ } & \multicolumn{3}{|c|}{ SOTON } \\
\hline & & & & $\mathrm{n}^{f}$ & Z & $\mathbf{p}$ & $\mathrm{n}^{f}$ & $\mathrm{Z}$ & $\mathbf{p}$ & $\mathrm{n}^{f}$ & $Z$ & $\mathbf{p}$ \\
\hline & & & & 188 & 3.08 & 0.0016 & 120 & 2.06 & 0.032 & 240 & -0.78 & 0.43 \\
\hline
\end{tabular}

SNP: single nucleotide polymorphism; MAF: minor allele frequency; FBAT: family-based association test. \#: the SNP showing a significant interaction with ETS using both FBAT homogeneity and Umbach-Weinberg tests in the EGEA discovery sample; ๆ: number of informative families; ${ }^{\S}$ : Chi-squared test 11 degree of freedom); ${ }^{f}$ : number of siblings (only one per family using the Umbach-Weinberg method).

difficult to detect. Genetic heterogeneity according to age is well documented. For instance, the effect of 17 q21 variants was found to differ according to age of onset of asthma [12, 26], and variants associated with exhaled fraction nitric oxide fraction $(F \mathrm{eNO})$ levels, an asthma-related phenotype, also differ in children and adults [32].

Another difficulty in replicating results across studies is that the SNP showing the most significant result (here interaction of rs7225157 with ETS) may not be the causal SNP, but a SNP in linkage disequilibrium with it. However, when we repeated our analysis with HapMap2-imputed SNPs in EGEA, a few interaction signals were observed which supported our initial result, but were less significant than this result. Thus, there was no indication that an imputed SNP might be the causal variant or in strong linkage disequilibrium with it and might have a better chance to be replicated in other samples. In addition, the linkage disequilibrium patterns between SNPs are not expected to differ between French and UK populations.

It is, however, noteworthy that interpretation of the imputation results should be conditioned by the possibility that some proportion of genetic variation has been missed.

Most previous interaction studies of genetic variants with ETS on asthma risk had difficulties in showing a significant interaction and/or replication in independent samples $[14,16,20]$. Indeed, replication of genexETS interaction is much more difficult to achieve than replication of single SNP association. The interaction tests are known to have low power and, moreover, as outlined earlier, there are many sources of heterogeneity between studies that are more crucial for detection of genexETS interaction than single SNP association. It should also be noticed that we applied here a particularly stringent strategy, which retained only SNPs showing significant interaction by two robust interaction tests. This strategy avoids false detection of interaction due to population stratification, but has consequently low power.

We verified that no association between the 17p11 locus and BHR, asthma or other lung function-related phenotypes has been reported by any of the published GWAS (www.genome.gov/gwastudies). Although a few gene $\times$ ETS interaction studies $[16,18]$ have been published for BHR to date, the $17 \mathrm{p} 11$ locus has never been mentioned. The SNP showing the significant interaction, i.e. rs7225157, is located in an intronic region of the DNAH9 gene (dynein, axonemal, heavy chain 9). The minor allele of the SNP is protective in ETS-unexposed siblings, but increases risk in exposed siblings. Examination of functional annotations using the HaploReg tool (http://compbio.mit.edu/HaploReg) and the UCSC Genome Browser (http:// genome.ucsc.edu) shows that the rs7225157 SNP and its proxies map to binding sites of various transcription factors. These transcription factors include FAC1 (fetal Alz-50-reactive clone 1), which was found to be associated with lung cancer and lung adenocarcinoma, CTCF (CCCTC-binding factor (zinc finger protein)), which plays a critical role in epigenetic regulation, NR4A1 (nuclear receptor subfamily 4 group A member 1), which was found associated with lung cancer in ETS-exposed subjects [33], and GATA2 (GATA binding protein 2), which was reported to be associated with an immunodeficiency disease (dendritic cell, monocyte lymphocyte, B and natural killer lymphoid deficiency) [34]. 
DNAH9 encodes the heavy chain subunit of axonemal dynein, a component of intra-flagellar transport responsible for cilia mobility. Interestingly, a loss of airway cilia mobility was associated with an increase in airway reactivity in mice [35]. In the airways of individuals who have asthma, some areas of the epithelial basement membrane seem to be denuded of ciliated cells [36]. DNAH9 is the most abundant isoform of the axonemal dynein heavy chain genes in ciliated cells of airways of the human body [37] and its expression has been recently reported to be downregulated in bronchial biopsies of patients with primary ciliary dyskinesia (PCD) [38], a disease associated with bronchiectasis and abnormalities of pulmonary function. BHR may play a part in the pathogenesis of bronchiectasis, the major pulmonary complication of PCD, by reducing the efficiency of respiratory clearance mechanisms, thereby promoting microbial colonisation and inflammation [39]. Finally, acute and chronic exposures to cigarette smoke were associated with an increase in dynein protein concentration in bronchoalveolar lavage, altered cilia motility in bovine and mouse lungs [40, 41], and epithelial epigenetic changes in the small airway epithelium [42].

All these observations showing the involvement of DNAH9 and ETS exposure in respiratory cilia mobility, which is linked to BHR, support our finding of a potential interactive effect of DNAH9 with ETS exposure on BHR. Interestingly, the recent GWIS for childhood asthma and ETS exposure [20] indicated interaction of ETS exposure with PACRG (Parkin coregulated gene), which, similar to DNAH9, has an important role in motile cilia function. Additionally, the pathway of cilia-related genes has been shown recently to be highly relevant to a biomarker of asthma, i.e. FeNO, by a bronchial epithelial cell gene expression study [43]. An immediate practical utility at the clinical level cannot be inferred from the results obtained in the framework of this genetic epidemiological study. However, taken together with the recent literature, our results add to the interest of studying cilia-related genes [44]. This emerging topic has already led to the identification of new genes correlated to clinical subphenotypes of asthma, suggesting that changes in ciliary function may be particularly relevant for the development of asthma in children.

In conclusion, the present study identified a promising candidate gene interacting with ETS exposure in BHR susceptibility. It highlights that genexenvironment interaction analyses, beyond single SNP association analysis, can greatly contribute to gene identification. Further confirmation of the interaction of DNAH9 with ETS exposure as well as functional studies are needed to bring better insight into the role of this gene in BHR.

\section{Acknowledgements}

We thank INSERM, French Ministry of Higher Education and Research, University Paris Diderot for supporting our research and the EGEA Cooperative Group.

EGEA Cooperative Group: coordination. V. Siroux (epidemiology, Principal Investigator since 2013); F. Demenais (genetics); I. Pin (clinical aspects); R. Nadif (biology); F. Kauffmann (Principal Investigator 1992-2012).

EGEA Cooperative Group: respiratory epidemiology. INSERM U700, Paris: M. Korobaeff (EGEA1), F. Neukirch (EGEA1); INSERM U707, Paris: I. Annesi-Maesano (EGEA1/2); INSERM CESP/U1018, Villejuif: F. Kauffmann, N. Le Moual, R. Nadif, M.P. Oryszczyn (EGEA1/2), R. Varraso; INSERM U823, Grenoble: V. Siroux.

EGEA Cooperative Group: genetics. INSERM U393, Paris: J. Feingold; INSERM U946, Paris: E. Bouzigon, F. Demenais, M.-H. Dizier; CNG, Evry: I. Gut (now CNAG, Barcelona, Spain), M. Lathrop (now McGill University, Montreal, Canada).

EGEA Cooperative Group: clinical centres. Grenoble: I. Pin, C. Pison; Lyon: D. Ecochard (EGEA1), F. Gormand, Y. Pacheco; Marseille: D. Charpin (EGEA1), D. Vervloet (EGEA1/2); Montpellier: J. Bousquet; Paris Cochin: A. Lockhart (EGEA1), R. Matran (now Lille); Paris Necker: E. Paty (EGEA1/2), P. Scheinmann (EGEA1/2); Paris-Trousseau: A. Grimfeld (EGEA1/2), J. Just.

EGEA Cooperative Group: data and quality management. INSERM ex-U155 (EGEA1): J. Hochez; INSERM CESP/ U1018, Villejuif: N. Le Moual; INSERM ex-U780: C. Ravault (EGEA1/2); INSERM ex-U794: N. Chateigner (EGEA1/2); Grenoble: J. Quentin-Ferran (EGEA1/2).

The authors thank all participants included in the SLSJ asthma familial collection. C. Laprise is the Chairholder of the Canada Research Chair on Genetic Determinants in Asthma (www.chairs-chaires.gc.ca), the Director of the Inflammation and Remodeling Strategic Group of the Respiratory Health Network of the Fonds de recherche du Québec

- Santé (http://rsr.chus.qc.ca), and a member of AllerGen (www.allergen-nce.ca).

\section{References}

1 Rage E, Siroux V, Le Moual N, et al. Re: Are asymptomatic airway hyperresponsiveness and allergy risk factors for asthma? A longitudinal study. Eur Respir J 2009; 33: 218-219.

2 March ME, Sleiman PM, Hakonarson H. Genetic polymorphisms and associated susceptibility to asthma. Int J Gen Med 2013; 6: 253-265.

3 Wjst M, Sargurupremraj M, Arnold M. Genome-wide association studies in asthma: what they really told us about pathogenesis. Curr Opin Allergy Clin Immunol 2013; 13: 112-118.

4 Ehrlich RI, Du Toit D, Jordaan E, et al. Risk factors for childhood asthma and wheezing. Importance of maternal and household smoking. Am J Respir Crit Care Med 1996; 154: 681-688.

5 Colilla S, Nicolae D, Pluzhnikov A, et al. Evidence for gene-environment interactions in a linkage study of asthma and smoking exposure. J Allergy Clin Immunol 2003; 111: 840-846. 
6 Meyers DA, Postma DS, Stine OC, et al. Genome screen for asthma and bronchial hyperresponsiveness: interactions with passive smoke exposure. J Allergy Clin Immunol 2005; 115: 1169-1175.

7 Dizier $\mathrm{MH}$, Bouzigon E, Guilloud-Bataille $\mathrm{M}$, et al. Evidence for gene $\times$ smoking exposure interactions in a genome-wide linkage screen of asthma and bronchial hyper-responsiveness in EGEA families. Eur J Hum Genet 2007; 15: 810-815.

8 Wang Z, Chen C, Niu T, et al. Association of asthma with $\beta_{2}$-adrenergic receptor gene polymorphism and cigarette smoking. Am J Respir Crit Care Med 2001; 163: 1404-1409.

9 Kabesch M, Hoefler C, Carr D, et al. Glutathione $S$ transferase deficiency and passive smoking increase childhood asthma. Thorax 2004; 59: 569-573.

$10 \mathrm{Wu}$ J, Hankinson J, Kopec-Harding $\mathrm{K}$, et al. Interaction between glutathione $S$-transferase variants, maternal smoking and childhood wheezing changes with age. Pediatr Allergy Immunol 2013; 24: 501-508.

11 Moffatt MF, Kabesch M, Liang L, et al. Genetic variants regulating ORMDL3 expression contribute to the risk of childhood asthma. Nature 2007; 448: 470-473.

12 Bouzigon E, Corda E, Aschard H, et al. Effect of 17q21 variants and smoking exposure in early-onset asthma. N Engl J Med 2008; 359: 1985-1994.

13 Flory JH, Sleiman PM, Christie JD, et al. 17q12-21 variants interact with smoke exposure as a risk factor for pediatric asthma but are equally associated with early-onset versus late-onset asthma in North Americans of European ancestry. J Allergy Clin Immunol 2009; 124: 605-607.

14 Blekic M, Kljaic Bukvic B, Aberle N, et al. 17q12-21 and asthma: interactions with early-life environmental exposures. Ann Allergy Asthma Immunol 2013; 110: 347-353.

15 van der Valk RJ, Duijts L, Kerkhof M, et al. Interaction of a $17 \mathrm{q} 12$ variant with both fetal and infant smoke exposure in the development of childhood asthma-like symptoms. Allergy 2012; 67: 767-774.

16 Koppelman GH, Meyers DA, Howard TD, et al. Identification of PCDH1 as a novel susceptibility gene for bronchial hyperresponsiveness. Am J Respir Crit Care Med 2009; 180: 929-935.

17 Van Eerdewegh P, Little RD, Dupuis J, et al. Association of the ADAM33 gene with asthma and bronchial hyperresponsiveness. Nature 2002; 418: 426-430.

18 Reijmerink NE, Kerkhof M, Koppelman GH, et al. Smoke exposure interacts with ADAM33 polymorphisms in the development of lung function and hyperresponsiveness. Allergy 2009; 64: 898-904.

19 Bukvic BK, Blekic M, Simpson A, et al. Asthma severity, polymorphisms in 20p13 and their interaction with tobacco smoke exposure. Pediatr Allergy Immunol 2013; 24: 10-18.

20 Scholtens S, Postma DS, Moffatt MF, et al. Novel childhood asthma genes interact with in utero and early-life tobacco smoke exposure. J Allergy Clin Immunol 2014; 133: 885-888.

21 Horvath S, Xu X, Laird NM. The family based association test method: strategies for studying general genotypephenotype associations. Eur J Hum Genet 2001; 9: 301-306.

22 Umbach DM, Weinberg CR. The use of case-parent triads to study joint effects of genotype and exposure. Am J Hum Genet 2000; 66: 251-261.

23 Kauffmann F, Dizier MH, Pin I, et al. Epidemiological study of the genetics and environment of asthma, bronchial hyperresponsiveness, and atopy: phenotype issues. Am J Respir Crit Care Med 1997; 156: S123-S129.

24 Laprise C. The Saguenay-Lac-Saint-Jean asthma familial collection: the genetics of asthma in a young founder population. Genes Immun 2014; 15: 247-255.

25 Sayers I, Barton S, Rorke S, et al. Allelic association and functional studies of promoter polymorphism in the leukotriene C4 synthase gene (LTC4S) in asthma. Thorax 2003; 58: 417-424.

26 Moffatt MF, Gut IG, Demenais F, et al. A large-scale, consortium-based genomewide association study of asthma. N Engl J Med 2010; 363: 1211-1221.

27 Lake SL, Blacker D, Laird NM. Family-based tests of association in the presence of linkage. Am J Hum Genet 2000; 67: 1515-1525.

28 Ege MJ, Strachan DP. Comparisons of power of statistical methods for gene-environment interaction analyses. Eur J Epidemiol 2013; 28: 785-797.

29 Kooperberg $\mathrm{C}$, Leblanc $\mathrm{M}$. Increasing the power of identifying gene $\times$ gene interactions in genome-wide association studies. Genet Epidemiol 2008; 32: 255-263.

30 Dizier MH, Margaritte-Jeannin P, Madore AM, et al. The nuclear factor I/A (NFIA) gene is associated with the asthma plus rhinitis phenotype. J Allergy Clin Immunol 2014; 134: 576-582.

31 Williams RL. A note on robust variance estimation for cluster-correlated data. Biometrics 2000; 56: 645-646.

32 Bouzigon E, Nadif R, Thompson EE, et al. A common variant in RAB27A gene is associated with fractional exhaled nitric oxide levels in adults. Clin Exp Allergy 2015; 45: 797-806.

33 Spitz MR, Gorlov IP, Amos CI, et al. Variants in inflammation genes are implicated in risk of lung cancer in never smokers exposed to second-hand smoke. Cancer Discov 2011; 1: 420-429.

34 Dickinson RE, Griffin H, Bigley V, et al. Exome sequencing identifies GATA-2 mutation as the cause of dendritic cell, monocyte, B and NK lymphoid deficiency. Blood 2011; 118: 2656-2658.

35 Gilley SK, Stenbit AE, Pasek RC, et al. Deletion of airway cilia results in noninflammatory bronchiectasis and hyperreactive airways. Am J Physiol Lung Cell Mol Physiol 2014; 306: L162-L169.

36 Xiao C, Puddicombe SM, Field S, et al. Defective epithelial barrier function in asthma. J Allergy Clin Immunol 2011; 128: 549-556.

37 Maiti AK, Mattei MG, Jorissen M, et al. Identification, tissue specific expression, and chromosomal localisation of several human dynein heavy chain genes. Eur J Hum Genet 2000; 8: 923-932.

38 Geremek M, Zietkiewicz E, Bruinenberg M, et al. Ciliary genes are down-regulated in bronchial tissue of primary ciliary dyskinesia patients. PLoS One 2014; 9: e88216.

39 Postma DS, de Vries K, Koeter GH, et al. Independent influence of reversibility of air-flow obstruction and nonspecific hyperreactivity on the long-term course of lung function in chronic air-flow obstruction. Am Rev Respir Dis 1986; 134: 276-280.

40 Sisson JH, Papi A, Beckmann JD, et al. Smoke and viral infection cause cilia loss detectable by bronchoalveolar lavage cytology and dynein ELISA. Am J Respir Crit Care Med 1994; 149: 205-213.

41 Simet SM, Sisson JH, Pavlik JA, et al. Long-term cigarette smoke exposure in a mouse model of ciliated epithelial cell function. Am J Respir Cell Mol Biol 2010; 43: 635-640. 
42 Buro-Auriemma LJ, Salit J, Hackett NR, et al. Cigarette smoking induces small airway epithelial epigenetic changes with corresponding modulation of gene expression. Hum Mol Genet 2013; 22: 4726-4738.

43 Modena BD, Tedrow JR, Milosevic J, et al. Gene expression in relation to exhaled nitric oxide identifies novel asthma phenotypes with unique biomolecular pathways. Am J Respir Crit Care Med 2014; 190: 1363-1372.

44 Bachmann-Gagescu R. Complexite genetique des ciliopathies et identification de nouveaux genes [Genetic complexity of ciliopathies and novel genes identification]. Med Sci (Paris) 2014; 30: 1011-1023. 